\title{
Application of multiple quench parameters for confirmation of radionuclide identity in radioanalytical quality control
}

\author{
Pawel Gaca ${ }^{1}$ [ $\cdot$ David Reading ${ }^{1} \cdot$ Phillip Warwick $^{1}$
}

Received: 18 July 2019 / Published online: 4 October 2019

(c) The Author(s) 2019

\begin{abstract}
Robust and reliable radiochemical analysis is the key factor in the appropriate disposal and management of radioactive wastes arising from the nuclear industry, decommissioning projects, medical, and scientific institutions. There is an ever increasing number of challenging projects that involve rapid analysis of large batches of samples and require rigorous quality control systems capable of positively identifying incorrect or questionable results which may lead to costly consequences at the latter stages of the waste disposal process. Combination of SQP(E) and SQPI LSC spectral parameters allows for quick and reliable checking of large datasets without the need for individual manual spectrum checks.
\end{abstract}

Keywords LSC measurement $\cdot$ SQP(E) $\cdot$ SQPI $\cdot$ Automated radionuclide purity check

\section{Introduction}

Radioactive waste sentencing in support of nuclear decommissioning relies on robust characterisation of waste streams. Quantification of difficult-to-measure radionuclides typically relies on chemical separation prior to liquid scintillation analysis to ensure that the target analyte is effectively separated from any radiometric interferences. Spectral deconvolution can be applied to correct for interferences that have co-extracted with the analyte. However, for beta emitting radionuclides, spectral deconvolution is not usually effective, particularly if the identity of the coextracted species is not known. Robust measurement therefore relies on efficient chemical separation alone. Confirmation of the effectiveness of the separation is usually achieved through visual inspection of spectra. This paper presents an alternative, less subjective, approach for the evaluation of liquid scintillation spectra in order to confirm the absence of radiometric interferences. The technique is based on an approach originally developed for identification of radioactive contaminants in emergency screening of drinking waters

Pawel Gaca

p.gaca@noc.soton.ac.uk

1 Faculty of Environmental and Life Sciences, Ocean and Earth Science, University of Southampton, National Oceanography Centre, European Way, Southampton SO14 3ZH, UK and uses multiple quench parameters to determine the mean energy of a beta emitting radionuclide, irrespective of the sample's quench [1]. The application of the technique to routine analysis is demonstrated using reference standards.

\section{Theory}

A typical beta radiation spectrum acquired using a liquid scintillation counter (LSC) shows continuous energy distribution with a nuclide-characteristic maximum energy $\left(\beta_{\max }\right)$, average energy where the intensity of the recorded spectrum is the highest ( $\beta_{\text {average }}$ ) and a gradual intensity decrease towards the low-energy part of the spectrum [2]. Examples of unquenched LSC spectra for several radionuclides using 1220 Quantulus ultra-low level liquid scintillation spectrometer are presented in Fig. 1.

One of the most significant obstacles which each analyst faces while performing an LSC measurement is spectral quench or a gradual degradation of the obtained spectrum due to a multitude of optical, chemical or physical reasons which leads to a reduction of counting efficiency and a shift of the observed energy of a beta decay. Examples of spectra affected by quench are presented in Fig. 2. All activity calculations based on LSC measurements must contain a counting efficiency correction to overcome problems created by quench presence. Usually, quench correction is being done using an electron movement within 

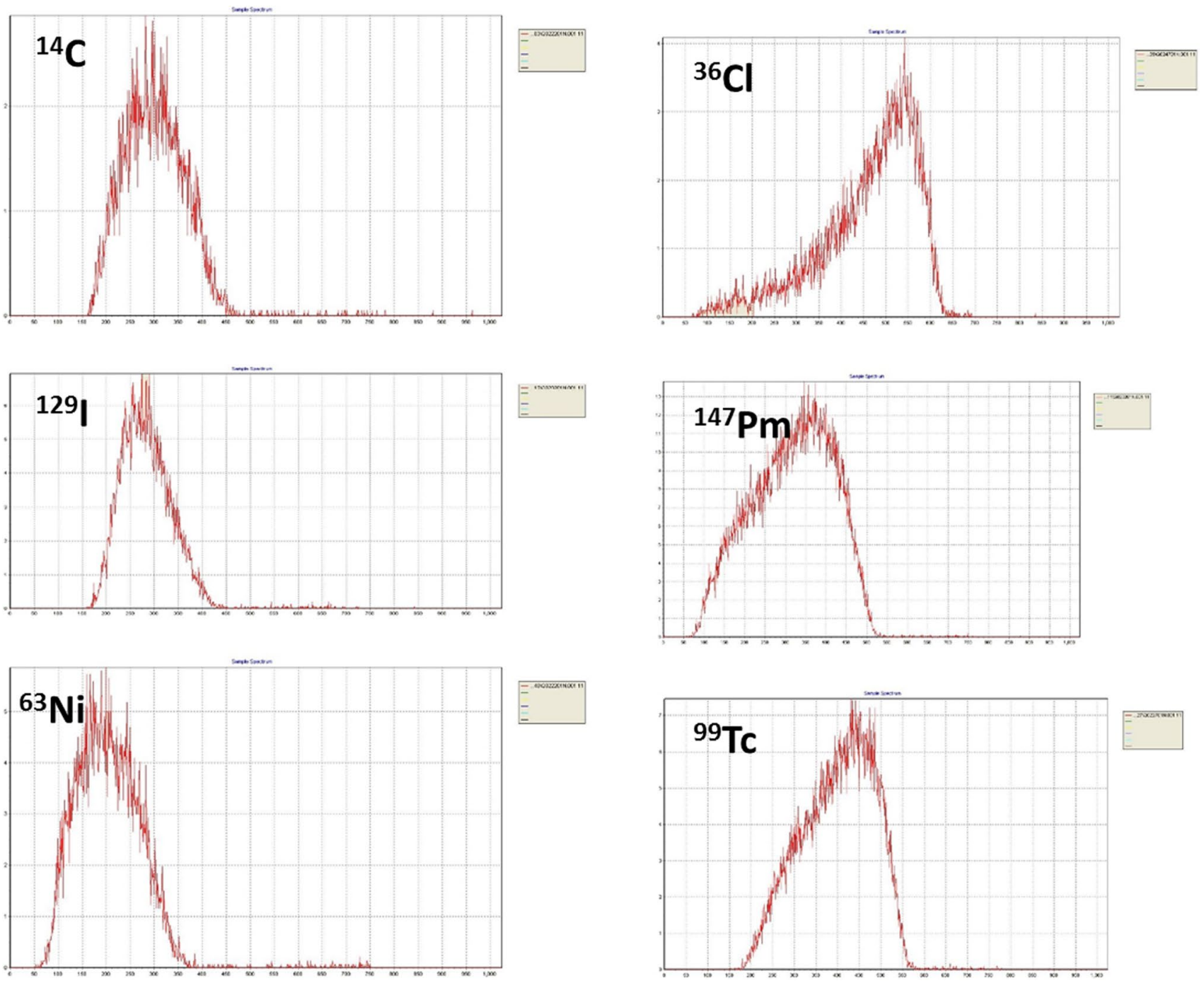

Fig. 1 Examples of radionuclide spectra obtained with 1220 Quantulus liquid scintillation spectrometer. The spectra were collected for unquenched (no quenching agent added) standards

the analysed sample which is induced by the presence of an external gamma radiation source (Compton effect) and registering the channel number below which $99 \%$ of the generated spectral counts reside (SQPE method, Fig. 3). For TriCarb instruments a tSIE term is used to describe similar quench correction technique. Another method is to observe a shift of a chosen point of a true LSC spectrum of an analysed radionuclide, for example, the point where $50 \%$ of counts are registered above and below on a channel scale (SQPI method, Fig. 4). [3] Again, for TriCarb instruments a term SIS is used to describe such approach.

Both SQP(E) and SQPI parameters depend on a quench level (Q) present in the sample. SQPI is also a function of energy $\left(\beta_{\max }\right)$ of the radionuclide which is being measured. A combination of both parameters allows to produce a new parameter (SQPI/SQP(E)), which now only depends on the energy:

(1) $\mathrm{SQPE}=f(Q)$

(2) $\mathrm{SQPI}=f\left(Q, \beta_{\max }\right)$

(3) $\mathrm{SQPI} / \mathrm{SQPE}=f\left(\beta_{\max }\right)$

Using SQPI/SQP(E) factor for single nuclide analysis enables identification of an unknown beta-emitting radionuclide by means of its $\beta_{\max }$ determination [3]

Interestingly, a ratio of SQPI factors determined at different spectral points e.g. SQPI(50) and SQPI(95) should remain constant throughout a wide quench level range. By analysing these parameters for a range of radionuclides it is possible to create a set of "peak shape factors" characteristic for each individual radionuclide. The presence of any other 

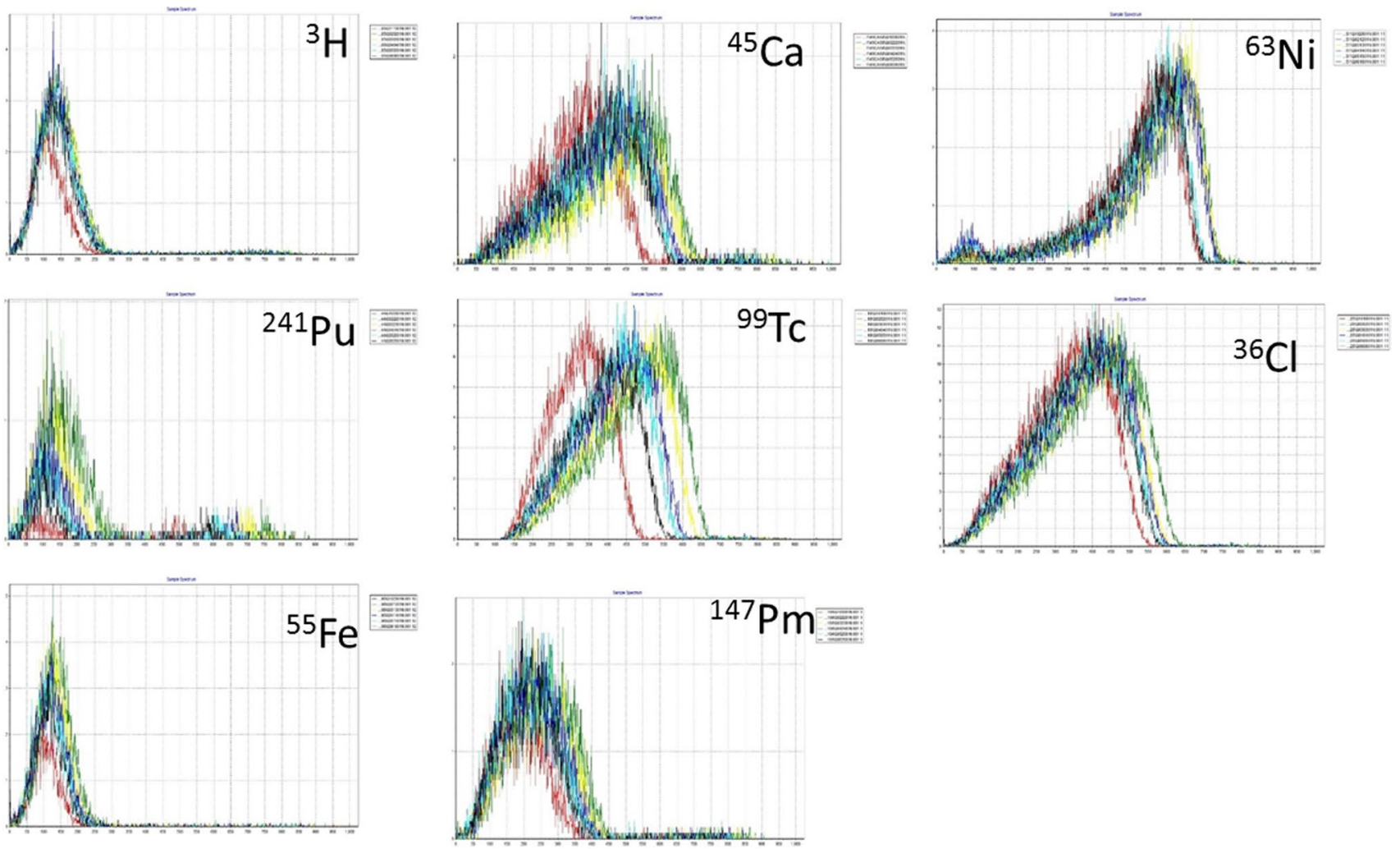

Fig. 2 Examples of spectral shift of beta spectra due to the presence of quench in analysed samples. SQPE range: ${ }^{3} \mathrm{H}(642-722),{ }^{241} \mathrm{Pu}(473-$ 756), ${ }^{55} \mathrm{Fe}(673-777),{ }^{45} \mathrm{Ca}(624-746),{ }^{99} \mathrm{Tc}(570-750),{ }^{147} \mathrm{Pm}(674-760),{ }^{63} \mathrm{Ni}(661-756),{ }^{36} \mathrm{Cl}(631-683)$

Fig. 3 Example of a gamma-ray induced LSC spectrum (Compton effect) and SQPE quench level check technique

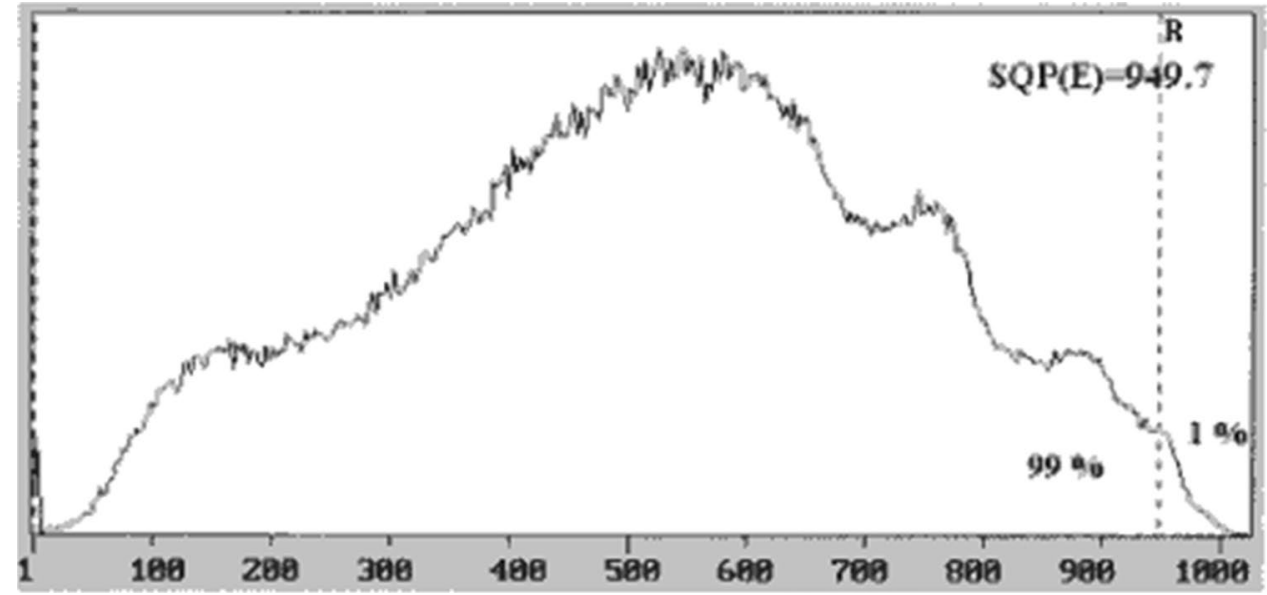

radionuclide in analysed purified samples will affect this "peak shape factor" by shifting the SQPI(95)/SQPI(50) away from the value determined for a clean, monoisotopic sample. Analysis of such ratio for large number of numerically recorded spectra allows a quick and easy way of verifying the purity of analysed samples and the validity of produced results.

By analysis of SQPI/SQPE ratio it is also possible to look for deviations in maximum beta radiation energy for the registered spectra and identify the samples which are outliers within larger analytical datasets.

Combination of both "peak shape factor" and SQPI/ SQPE checks for each registered spectrum and building them into a simple software or calculation spreadsheet should become a useful tool in quality assurance diagnostics of the produced samples. 

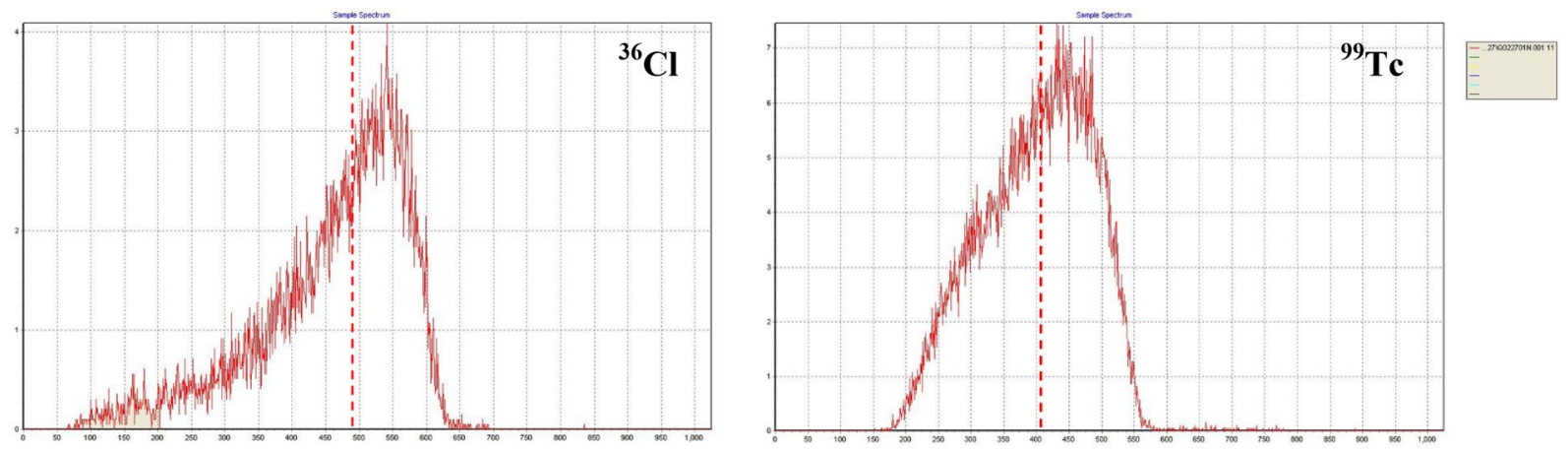

Fig. 4 Examples of LSC spectra of ${ }^{36} \mathrm{Cl}$ and ${ }^{99} \mathrm{Tc}$ with SQPI(50) marked with dotted lines. 50\% of all registered counts are recorded above or below the marked position. The position of the SQPI(50) on a channel/energy scale depends on the quench level in the sample

Table 1 Summary of radionuclides used for clean standard SQPI(95)/ SQPI(50) parameter

\begin{tabular}{llll}
\hline Radionuclide & $\begin{array}{l}\text { Maximum } \\
\text { beta energy } \\
\left(\beta_{\max }\right)(\mathrm{keV})\end{array}$ & $\begin{array}{l}\text { SQPI(95)/SQPI(50) } \\
\text { "peak shape factor" }\end{array}$ & SQPE range \\
\hline${ }^{3} \mathrm{H}$ & 18.571 & $1.43 \pm 0.04^{\mathrm{a}}(1.34-1.46)^{\mathrm{b}}$ & $642-722$ \\
${ }^{63} \mathrm{Ni}$ & 65.87 & $1.54 \pm 0.02(1.51-1.56)$ & $661-756$ \\
${ }^{147} \mathrm{Pm}$ & 224.1 & $1.46 \pm 0.02(1.43-1.48)$ & $674-760$ \\
${ }^{45} \mathrm{Ca}$ & 256.9 & $1.43 \pm 0.03(1.38-1.47)$ & $624-746$ \\
${ }^{99} \mathrm{Tc}$ & 293.6 & $1.282 \pm 0.006(1.27-$ & $570-750$ \\
& & $1.29)$ & \\
${ }^{36} \mathrm{Cl}$ & 709.6 & $1.22 \pm 0.01(1.20-1.24)$ & $631-683$ \\
\hline
\end{tabular}

${ }^{a}$ Average value for all analysed standards. Uncertainty is \pm 1 S.D. (1 $\left.\sigma\right)$

${ }^{b}$ Range of "peak shape factors" calculated for individual standards

\section{Experimental}

A set of test samples spiked with a known amount of a monoisotopic standard solutions traceable to NPL, PTB or NIST and with varying levels of quench were counted using 1220 Quantulus liquid scintillation spectrometer. The method of a varying quench level standard solution preparation used for LSC spectrometer's calibration was described in detail in a previous publication and a user manual for 1220 Quantulus LSC spectrometer [4, 5]. For each collected spectrum the SQPI(95) and SQPI(50) parameters were determined. Quench level in the measured sources was determined using a built-in SQPE check feature of a 1220 Quantulus spectrometer which utilises a ${ }^{152} \mathrm{Eu}$ source [6]. The summary of radionuclides used in the experiment and quench levels are included in Table 1 together with the determined "peak shape factor" values.

For all the radionuclides listed in Table 1 the SQPI(95)/ SQPE parameter was calculated and the results plotted versus maximum beta energy. To check the behaviour of both "peak shape factor" and SQPI(95)/SQPE parameters in the presence of another radionuclide in the analysed sample, a series of ${ }^{63} \mathrm{Ni}$ standards spiked with ${ }^{3} \mathrm{H}$ (low-energy beta emitter), ${ }^{99} \mathrm{Tc}$ (mid-energy beta emitter) and ${ }^{36} \mathrm{Cl}$ (high-energy beta emitter) were produced. To check how a varying amount of a contaminating radionuclide affects the parameters of interest, ${ }^{63} \mathrm{Ni}$ standards were spiked with varying activities of ${ }^{3} \mathrm{H}$ and ${ }^{99} \mathrm{Tc}$ to observe the effect of a lower and higher energy emitter presence. The influence of a gamma radiation emitter was tested using, a set of ${ }^{63} \mathrm{Ni}$ standards spiked with varying amount of ${ }^{85} \mathrm{Sr}$ (gamma emission at $514 \mathrm{keV}$ ). The effect of an alpha emitter presence was checked by spiking ${ }^{63} \mathrm{Ni}$ standards with ${ }^{242} \mathrm{Pu}$ (alpha emissions at: $4.901 \mathrm{MeV}$ and $4.856 \mathrm{MeV}$, efficiency of ca. $76.5 \%$ and $23.5 \%$, respectively) and ${ }^{236} \mathrm{U}$ (alpha emissions at 4.824 MeV and 4.445 MeV, efficiency ca. $77.5 \%$ and $22.4 \%$, respectively) solutions. For all the above spiked ${ }^{63} \mathrm{Ni}$ standards "peak shape factor" and SQPI(95)/SQPE factors were calculated. The choice of ${ }^{63} \mathrm{Ni}$ as a reference radionuclide in the above described tests was determined by standard availability and the fact that ${ }^{63} \mathrm{Ni}$ is one of the most frequently analysed radionuclides in the samples originating from nuclear installations and decommissioning projects.

\section{Results and discussion}

The results of a "peak shape factor", or SQPI(95)/SQPI(50) determination obtained for clean, monoisotopic standard solutions with varying quench levels are presented in Table 1. Results of a SQPI(95)/SQPE parameter determinations for monoisotopic sources are presented in Fig. 5.

The results collected in Table 1 show that the ratio between SQPI(95) and SQPI(50) remains reasonably constant for each tested radionuclide within a wide range of quench present in the analysed standards. Averaged values calculated for all the tested radionuclides are: $1.43 \pm 0.04$ $\left({ }^{3} \mathrm{H}\right), 1.54 \pm 0.02\left({ }^{63} \mathrm{Ni}\right), 1.46 \pm 0.02\left({ }^{147} \mathrm{Pm}\right), 1.43 \pm 0.03$ $\left({ }^{45} \mathrm{Ca}\right), 1.282 \pm 0.006\left({ }^{99} \mathrm{Tc}\right)$ and $1.22 \pm 0.01\left({ }^{36} \mathrm{Cl}\right)$, 
Fig. 5 SQPI(95)/SQPE parameters calculated for monoisotopic standards with varying amount of quench. Refer to Table 1 for SQPE range

Table 2 SQPI(95)/SQPI(50) or "peak shape factor", SQPI(95)/SQPE and SQPI(50)/ SQPE factors for ${ }^{63} \mathrm{Ni}$ sources both clean and mixed with a contaminating radionuclides: ${ }^{3} \mathrm{H},{ }^{99} \mathrm{Tc},{ }^{36} \mathrm{Cl}$

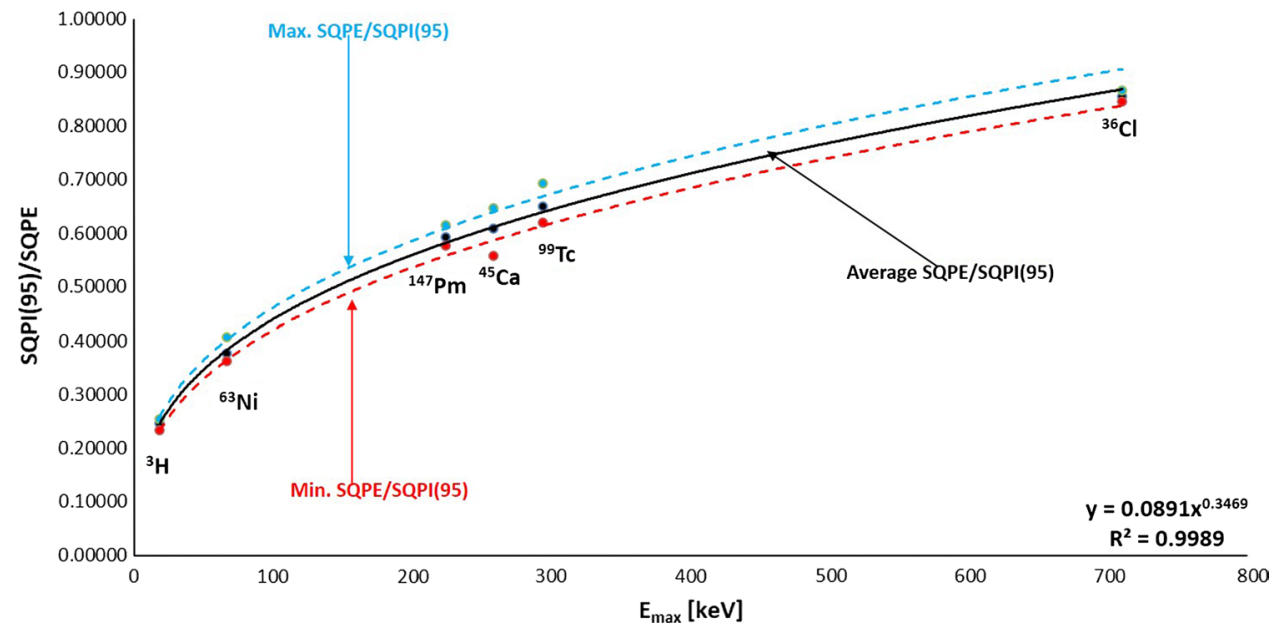

\begin{tabular}{|c|c|c|c|c|c|c|}
\hline \multirow[t]{2}{*}{ Contaminant } & \multicolumn{2}{|c|}{ SQPI(95)/SQPI(50) } & \multicolumn{2}{|c|}{ SQPI(95)/SQPE } & \multicolumn{2}{|c|}{ SQPI(50)/SQPE } \\
\hline & Mixed & Clean & Mixed & Clean & Mixed & Clean \\
\hline${ }^{3} \mathrm{H}$ & 1.796 & $1.54 \pm 0.02$ & 0.384 & $0.38 \pm 0.02$ & 0.214 & $0.245 \pm 0.008$ \\
\hline${ }^{99} \mathrm{Tc}$ & 1.763 & & 0.671 & & 0.38 & \\
\hline${ }^{36} \mathrm{Cl}$ & 1.381 & & 0.864 & & 0.625 & \\
\hline
\end{tabular}

respectively. Uncertainties reported are standard deviation values $(1 \sigma)$.

Table 2 summarises the results of a clean, monoisotopic ${ }^{63} \mathrm{Ni}$ standard analysis and after it was spiked with ${ }^{3} \mathrm{H},{ }^{99} \mathrm{Tc}$ and ${ }^{36} \mathrm{Cl}$. The values for mixed solutions are calculated based on numbers derived from a single spectrum. The values for clean sources are average values obtained for a series of spectra obtained for SQPE parameter between 661 and 756 which represent high and low level of quench for the spectrometer that was used during the experiment. Uncertainty values reported for clean ${ }^{63} \mathrm{Ni}$ solutions are standard deviation values for the calculated averages (1 $\sigma$ ). SQPI/ SQPE factor is presented for two SQPI values: 95 and 50 to allow a comparison of a scale of the value change at different SQPI values. For the nuclide systems considered in this experiment, the SQPI(50)/SQPE parameter values are: $0.214,0.380$ and 0.625 for the addition of ${ }^{3} \mathrm{H},{ }^{99} \mathrm{Tc}$ and ${ }^{36} \mathrm{Cl}$, respectively. These values seem to differ more distinctively from a clean standard parameter of $0.245 \pm 0.008$ than the values obtained for SQPI(95)/SQPE parameter. In the latter case, the parameter values are $0.384,0.671$ and 0.864 while clean ${ }^{63} \mathrm{Ni}$ signal produces value of $0.380 \pm 0.020$. Although data spread for SQP(95)/SQPE offer a wider spread the number calculated after ${ }^{3} \mathrm{H}$ addition lies very close to a clean standard value which makes the distinction between "clean" and "dirty" spectrum difficult.

Images presented in Fig. 6 show the mixed $\left({ }^{63} \mathrm{Ni}+\right.$ contaminant) LSC spectra. Comparison of the visual spectrum check and the shift of the multiparametral quench factors both, as expected, show deviations from the image and values obtained for clean ${ }^{63} \mathrm{Ni}$ standard solution.

Varying amount of contaminant present in the sample is also results in a changing value of both "peak shape factor" and SQPI/SQPE parameters. Table 3 presents the data obtained for ${ }^{63} \mathrm{Ni}$ solution spiked with increasing amount of ${ }^{3} \mathrm{H}$ and ${ }^{99} \mathrm{Tc}$. Peak shape factor changes from 1.582 to 1.845 following the additions of increasing amount of ${ }^{3} \mathrm{H}$. Compared to a value obtained for clean ${ }^{63} \mathrm{Ni}$ presented in Table $2(1.54 \pm 0.02)$ it becomes visible that by using "peak shape factor" analysis even relatively small amount of ${ }^{3} \mathrm{H}$ present in ${ }^{63} \mathrm{Ni}$ sample can be detected while visual check of a slightly contaminated spectrum may not reveal the presence of a small amount of a contaminant. Similarly, the ${ }^{99} \mathrm{Tc}$ peak shape parameter value shifts from 2.127 to 1.805. Images illustrating the changes of ${ }^{63} \mathrm{Ni}$ spectra with the addition of ${ }^{3} \mathrm{H}$ and ${ }^{99} \mathrm{Tc}$ are presented in Fig. 7. Because of the maximum beta energy difference between two components of a spectrum is higher for ${ }^{63} \mathrm{Ni}-{ }^{99} \mathrm{Tc}$ system than for ${ }^{63} \mathrm{Ni}-{ }^{3} \mathrm{H}$ system, the calculated parameters shift from clean ${ }^{63} \mathrm{Ni}$ signal is of course much higher in case of ${ }^{99} \mathrm{Tc}$ contamination. Such dependence of the SQPI/SQPE parameters on the energy difference between two radionuclides is presented in Fig. 8.

Addition of an alpha emitter to ${ }^{63} \mathrm{Ni}$ standard shifts SQPI(95)/SQPI(50) value to 2.910 and 2.799 for ${ }^{242} \mathrm{Pu}$ and ${ }^{236} \mathrm{U}$ respectively. Activities of the alpha emitters used during the experiment were approximately 10 times lower than ${ }^{63} \mathrm{Ni}$ activity. Likewise, SQPI/SQPE parameter values for 

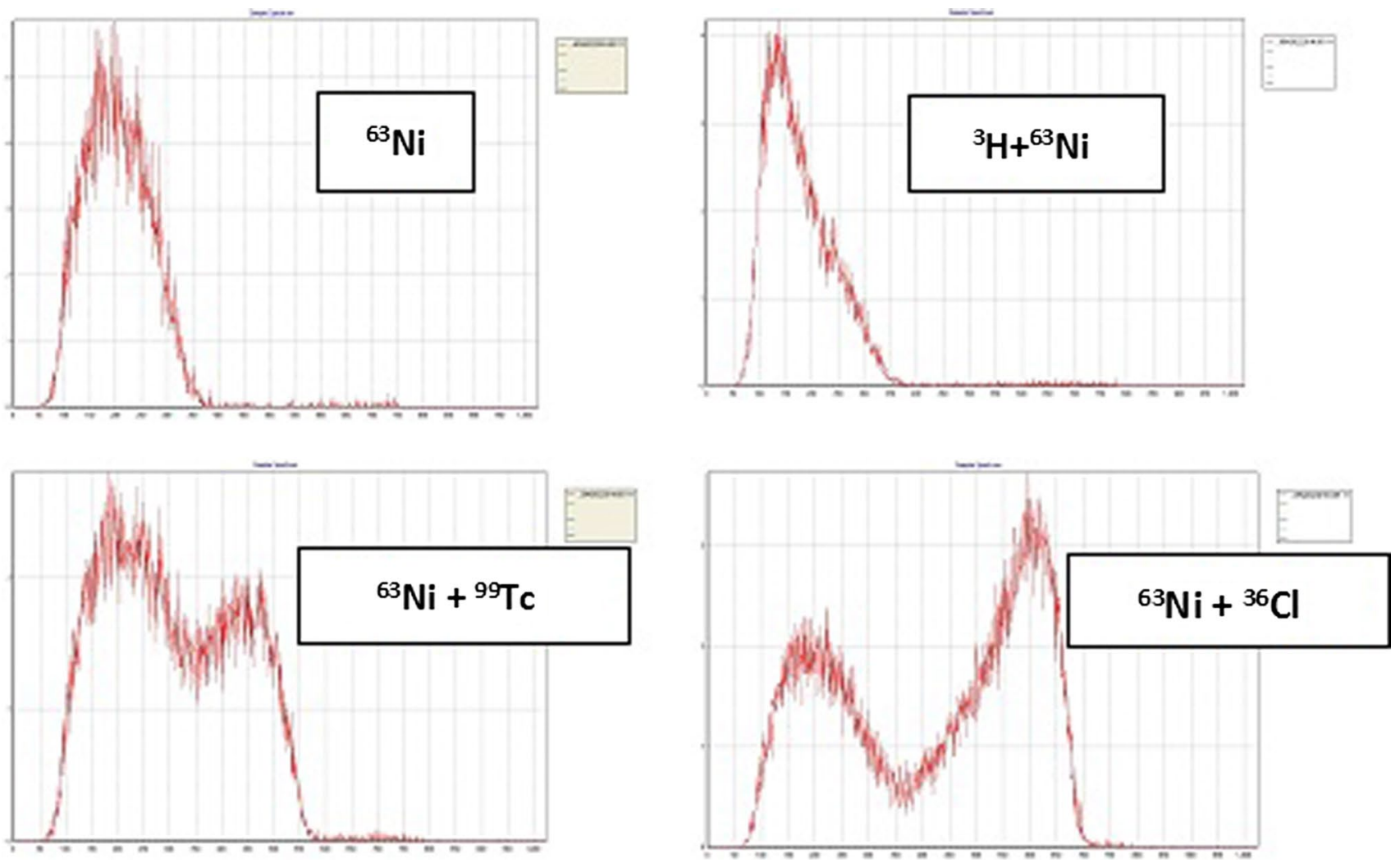

Fig. 6 Examples of ${ }^{63} \mathrm{Ni}$ spectra $(A \approx 7 \mathrm{~Bq})$ spiked with ${ }^{3} \mathrm{H}(A \approx 9 \mathrm{~Bq}),{ }^{99} \mathrm{Tc}(A \approx 8 \mathrm{~Bq})$ and ${ }^{36} \mathrm{Cl}(A \approx 10 \mathrm{~Bq})$. For comparison a pure ${ }^{63} \mathrm{Ni}$ spectrum is also included. Corresponding multiparametral quench parameters for the presented spectra were reported in Table 2

Table 3 Peak shape factors and SQPI/SQPE parameter value change with the increasing amount of contaminant $\left({ }^{3} \mathrm{H}\right.$ or $\left.{ }^{99} \mathrm{Tc}\right)$ present in ${ }^{63} \mathrm{Ni}$ solution

\begin{tabular}{llllll}
\hline${ }^{3} \mathrm{H}[\mathrm{Bq}]$ & ${ }^{63} \mathrm{Ni}[\mathrm{Bq}]$ & ${ }^{63} \mathrm{Ni} /{ }^{3} \mathrm{H}$ activity ratio & SQPI(95)/SQPI(50) & SQPI(95)/SQPE & SQPI(50)/SQPE \\
\hline 2.7 & 14.2 & 5.3 & 1.582 & 0.400 & 0.253 \\
5.4 & 14.0 & 2.6 & 1.637 & 0.398 & 0.243 \\
10.6 & 14.2 & 1.3 & 1.718 & 0.389 & 0.227 \\
17.7 & 14.2 & 0.8 & 1.775 & 0.379 & 0.213 \\
35.3 & 14.2 & 0.4 & 1.845 & 0.368 & 0.200 \\
${ }^{99} \mathrm{Tc}[\mathrm{Bq}]$ & ${ }^{63} \mathrm{Ni}[\mathrm{Bq}]$ & ${ }^{63} \mathrm{Ni} /{ }^{99} \mathrm{Tc}$ activity ratio & $\mathrm{SQPI}(95) / \mathrm{SQPI}(50)$ & $\mathrm{SQPI}(95) / \mathrm{SQPE}$ & $\mathrm{SQPI}(50) / \mathrm{SQPE}$ \\
3.8 & 14.2 & 3.8 & 2.127 & 0.627 & 0.295 \\
5.2 & 14.2 & 2.7 & 2.11 & 0.635 & 0.301 \\
7.5 & 14.2 & 1.9 & 2.025 & 0.648 & 0.320 \\
9.8 & 14.2 & 1.5 & 1.941 & 0.660 & 0.340 \\
13.9 & 14.2 & 1.0 & 1.805 & 0.668 & 0.368 \\
\hline
\end{tabular}

both SQPI(95) and SQPI(50) show clear shift towards values characteristic for higher maximum beta energy and the calculated results were: 0.752 and 0.680 for ${ }^{242} \mathrm{Pu}(\mathrm{SQPI}(95))$ and 0.258 and 0.243 for ${ }^{236} \mathrm{U}$ (SQPI(50)).

Addition of varying amount of ${ }^{85} \mathrm{Sr}$ to ${ }^{63} \mathrm{Ni}$ standard allows to check the effect of gamma radiation on the resulting spectral quench parameters. In this case, visual check of the recorded spectrum may not reveal any contamination, also SQPI/SQPE parameters values remain relatively stable. SQPI(95)/SQPI(50) values change noticeably with the increasing amount of ${ }^{85} \mathrm{Sr}$ and change from value identical to a clean ${ }^{63} \mathrm{Ni}$ spectrum (1.541) to 1.620 . Table 4 summarises the obtained results for ${ }^{85} \mathrm{Sr}-{ }^{63} \mathrm{Ni}$ system and lack of any significant visual change of the ${ }^{63} \mathrm{Ni}$ spectrum can be observed in Fig. 9. 

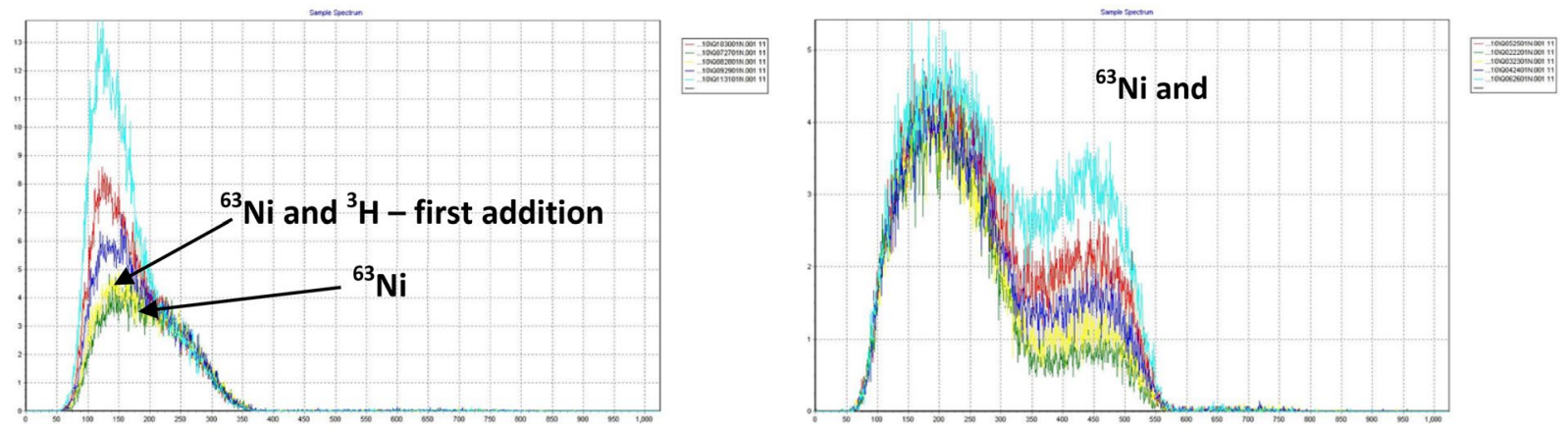

Fig. $7{ }^{63} \mathrm{Ni}$ LSC spectra with varying amount of added ${ }^{3} \mathrm{H}$ (left) and ${ }^{99} \mathrm{Tc}$ (right). Activities of ${ }^{63} \mathrm{Ni}$ and contaminants are presented in Table 3

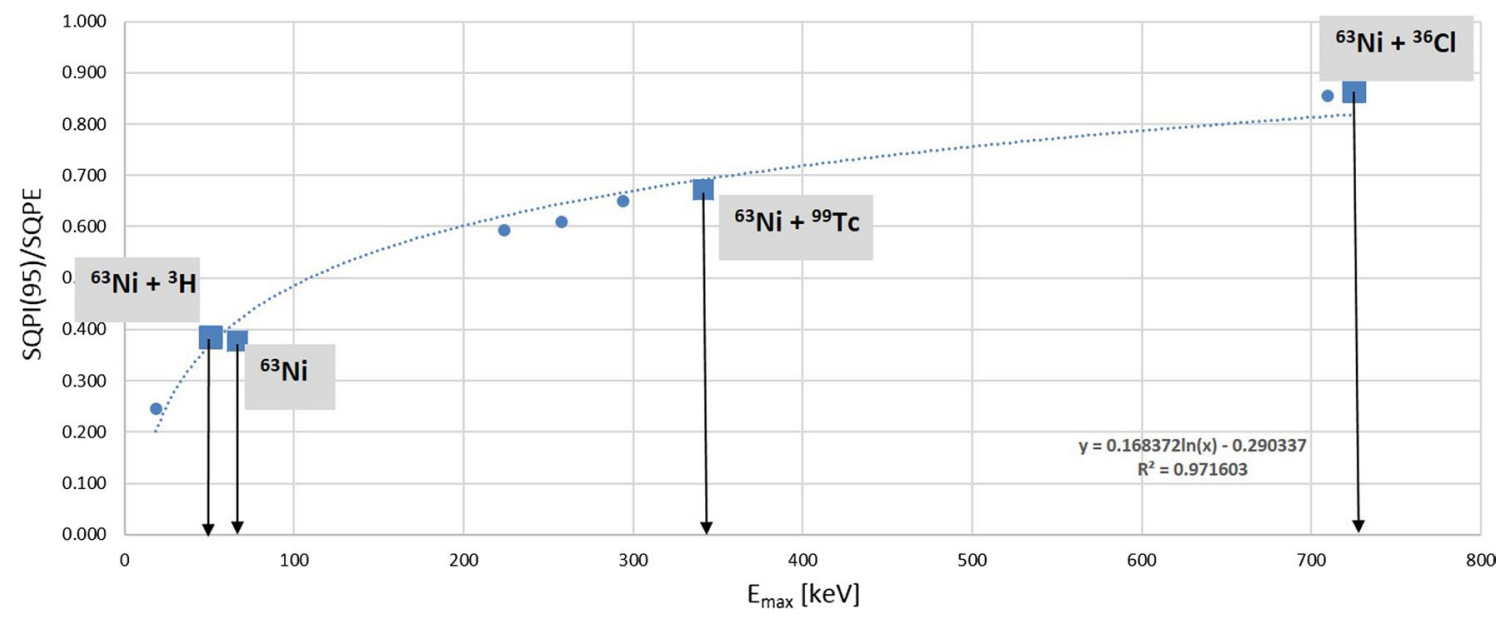

Fig. 8 SQPI(95)/SQPE parameter value change for ${ }^{63} \mathrm{Ni}$ standard spiked with ${ }^{3} \mathrm{H},{ }^{99} \mathrm{Tc}$ and ${ }^{36} \mathrm{Cl}$

Table 4 Effect of ${ }^{85} \mathrm{Sr}$ addition on spectral parameters of ${ }^{63} \mathrm{Ni}$ spectrum

\begin{tabular}{llllll}
\hline${ }^{85} \mathrm{Sr}[\mathrm{Bq}]$ & ${ }^{63} \mathrm{Ni}[\mathrm{Bq}]$ & $\begin{array}{l}{ }^{63} \mathrm{Ni} /{ }^{85} \mathrm{Sr} \text { activ- } \\
\text { ity ratio }\end{array}$ & $\begin{array}{l}\text { SQPI(95)/ } \\
\text { SQPI(50) }\end{array}$ & SQPI(95)/SQPE & SQPI(50)/SQPE \\
\hline 0.5 & 14.3 & 31.0 & 1.582 & 0.400 & 0.253 \\
0.9 & 14.2 & 15.4 & 1.637 & 0.398 & 0.243 \\
1.8 & 14.2 & 7.7 & 1.718 & 0.389 & 0.227 \\
2.8 & 14.2 & 5.1 & 1.775 & 0.379 & 0.213 \\
3.7 & 14.3 & 3.9 & 1.845 & 0.368 & 0.200 \\
\hline
\end{tabular}

\section{Conclusions}

Multiparametral quench analysis is a promising approach to spectrum quality check during LSC analysis. It may be especially beneficial when applied to large datasets where manual checking of spectra becomes time intensive and is susceptible to errors, misinterpretation and omittance. Accurate determination of SQPI parameters rely on a good quality spectrum which is easily attainable for high activity samples but lower activity samples will require extended counting periods in order to produce reliable calculations for SQPI. Despite this, the efficiency in which an analyst can deduce potential contamination is greatly improved by not having to manually assess spectra and by reducing the likelihood of misinterpreting data and thus saves time.

Calculating "peak shape parameters" or SQPI/SQPE values is relatively easy to achieve using specially written software or from a simple calculation spreadsheet. By observing the direction of change of SQPI/SQPE parameter, it is possible to draw conclusions about the beta energy of a contaminant present in the sample. A negative shift to lower 


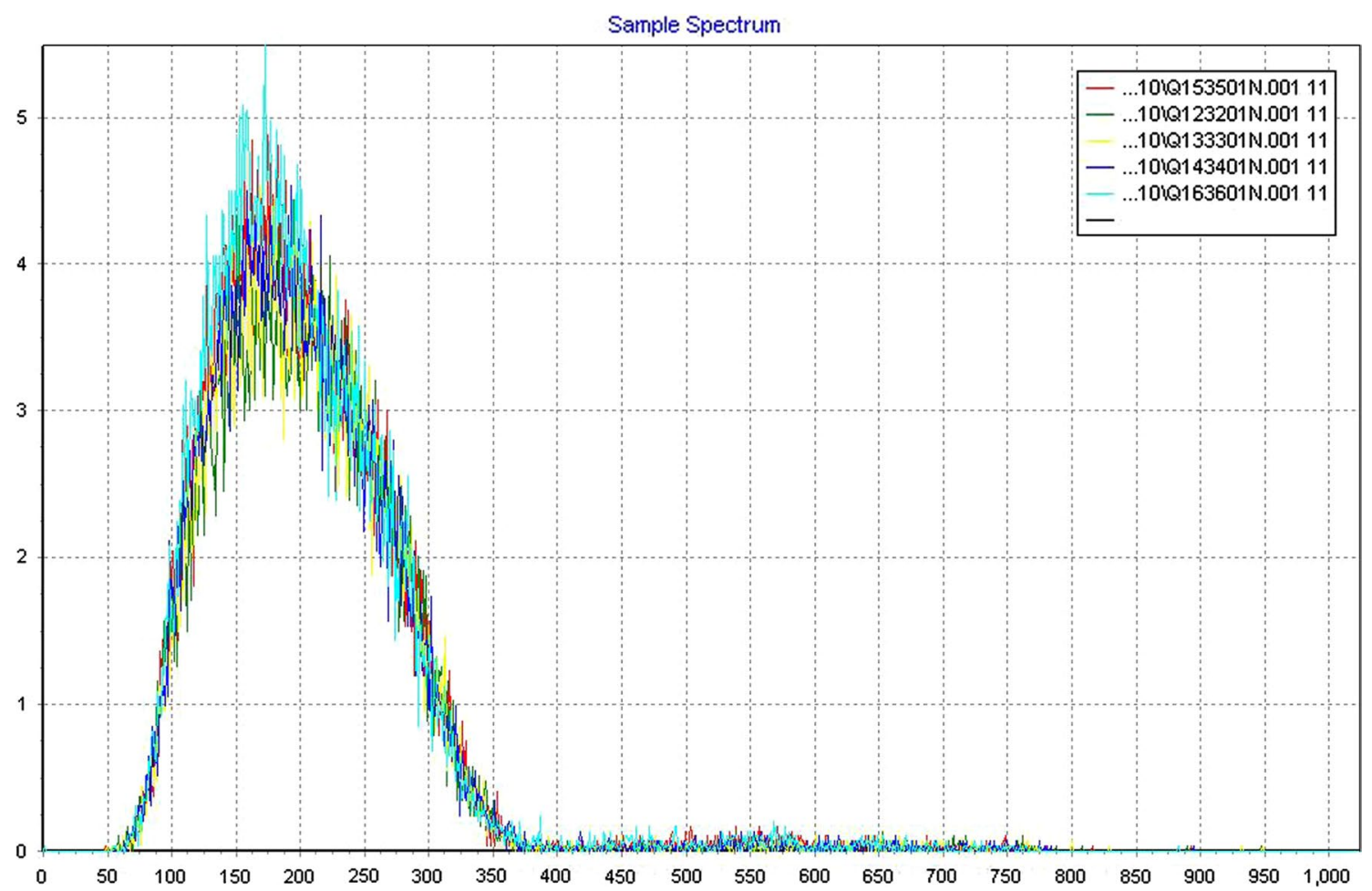

Fig. 9 Effect of ${ }^{85} \mathrm{Sr}$ addition (varying amounts) on spectral parameters of ${ }^{63} \mathrm{Ni}$ spectrum. No definite visual effect can be seen

values indicates the presence of a beta emitter with the $\beta_{\max }$ energy lower than the analysed radionuclide while a positive shift indicates that contamination is caused by a higher energy beta emitter.

By careful analysis of monoiosotopic standards with varying amount of quench, it is possible to build a database for a wide range of radionuclides and optimise the quench parameters which are most useful in purity assessment of any given radionuclide.

Open Access This article is distributed under the terms of the Creative Commons Attribution 4.0 International License (http://creativeco mmons.org/licenses/by/4.0/), which permits unrestricted use, distribution, and reproduction in any medium, provided you give appropriate credit to the original author(s) and the source, provide a link to the Creative Commons license, and indicate if changes were made.

\section{References}

1. Annunziata MF, Kessler MJ (2012) In: Annunziata MF (ed) Handbook of radiochemical analysis, 3rd edn. Academic Press, Oxford
2. McCormac FG (1992) Liquid Scintillation counter characterization, optimization and benzene purity correction. Radiocarbon 34(1):37-45

3. Warwick PE, Croudace IW (2013) Identification and quantification of radionuclides in contaminated drinking waters and pipeline deposits. Anal Chem 85(17):8166-8172. https://doi.org/10.1021/ ac401131t

4. Gaca P, Warwick P, Croudace I (2017) Liquid scintillation counters calibration stability over long timescales. J Radioanal Nucl Chem 314(2):753-760. https://doi.org/10.1007/s1096 7-017-5388-6

5. Use and preparation of quench curves in LSC. https://www.perki nelmer.com/liquidscintillation/images/APP_Use-and-Preparatio n-of-Quench-Curves-in-LSC_tcm151-171749.pdf. Accessed 15 Jul 2019

6. Wallac 1220 Quantulus Ultra Low Level Liquid Scintillation Spectrometer Instrument Manual. https://www.perkinelmer.com/ content/manuals/gde_quantulusinstrumentmanual.pdf. Accessed $15 \mathrm{Jul} 2019$

Publisher's Note Springer Nature remains neutral with regard to jurisdictional claims in published maps and institutional affiliations. 